\title{
Business Operation Approach of Small and Medium Enterprise in Pathumthani Province
}

\author{
Pensri Bangbon ${ }^{1}$, Thanakorn Thanathanchuchot ${ }^{2}$, Yannakorn Toprayoon ${ }^{3}$, Chantip \\ Chumdermpadejsuk ${ }^{4}$ \\ ${ }^{1}$ Pacific Institute of Management Science \\ ${ }^{2}$ Pathumthani University, \\ ${ }^{3}$ The Association of Researchers of Thailand. \\ ${ }^{4}$ Ramkhamhaeng University \\ ${ }^{1}$ pensri.2508@gmail.com, ${ }^{2}$ dr.thanakorn@gmail.com, ${ }^{3}$ yannakorn1978@gmail.com ${ }^{4}$ mysunshine899@gmail.com
}

\begin{abstract}
The purposes of this research are to study; 1) The importance level of factors lead to the business operations approach of SMEs 2) The characteristic of SMEs. 3) The relationship between the characteristic of SMEs and the importance level of factors lead to the business operations approach of SMEs. 4) Business operation approach of Small and Medium Enterprise in Pathumthani Province. Research via quantitative methodology. Data were collected from the executive or owner of SMEs in Pathumthani Province, by accidental sampling of 385 respondents of unknown exactly population. The research instrument were questionnaires. The data were then analyzed by computer software packages, statistic treatments were frequency, percentage, means, standard deviation, and ranking, Pearson Correlation, and Multiple Regression at statistical significance level of .05 The results of the research were as follows: 1) Overall the importance level of factors lead to the business operations approach of SMEs in Pathumthani Province were at of a high importance level, raked by CV (Covariant) respectively were: Technology Development and upgrading of firms' technology, Innovation and information technology, Products, Distribution and supply chain, Business Environment, Price, Government promotion, Market promotion. 2) Overall and individual of the characteristic of SMEs in Pathumthani Province were at of a high importance level, raked by CV (Covariant) respectively were Average total turnover per year, .Amount of employees, SMEs business operation.3) There were moderate relationship level between the characteristic of SMEs and the importance level of factors lead to the business operations approach of SMEs in Pathumthani Province. 4) Business operation approach of Small and Medium Enterprises in Pathumthani Province = was 0.783 Government promotion, was 0.775 Innovation, was 0.771 Technology Development and upgrading of firms' technology, was 0.702 Distribution and supply chain, was 0.681 Products, was 0.641 Price, $\quad$ was 0.421 Market promotion. $(\mathrm{R}$ square $=$
\end{abstract} $0.851)$

Index Terms

Business operation approach, SMES

Article Received: 10 August 2020, Revised: 25 October 2020, Accepted: 18 November 2020

\section{Introduction}

The world economy is slowing down. Thailand has not been spared. The Asian Development Bank has lowered its growth forecast to a modest $2.7 \%$ for the year. Former finance minister and central bank chairman Virabongsa Ramangkura recently warned that the slowdown could last as long as five years. Small and medium-sized enterprises feature prominently in the government's strategy to stimulate growth and development, with a recent plan calling for boosting credit to smaller firms and encouraging them to expand into regional and global markets. The focus on SMEs is appropriate. Economies with lots of thriving SMEs are more dynamic and competitive than those dominated by a handful of sclerotic giants. More importantly, successful SMEs are critical drivers of inclusive growth, according to new research from the International Trade Centre (ITC), the joint agency of the United Nations and the World Trade Organization. [1]

But helping SMEs The content explains the meaning of risk, the meaning of cost, importance of risk of cost, and concept of Enterprise Risk Management related with organizational survival. Hence, the SMEs entrepreneurs should have realized the importance of risk of cost together with continuous improvement in order to gain sustainable competitive advantage.[2]

Large companies everywhere tend to be more productive than small ones. But the gap in productivity is far wider in developing countries. Low productivity in turn means lower wages and worse working conditions. This productivity gap has a silver lining: there is a lot of room to improve. Improving SMEs productivity translates into more and better paying jobs, distributed across less fortunate sections of the economy. SMEs able to "internationalize", whether by exporting or importing directly or selling to firms that do, register particularly high productivity, wage, and employment gains. Encouraging Thai SMEs to reach out to Asean markets and beyond clearly makes a lot of sense. But while helping SMEs become more productive and competitive makes for inclusive growth, figuring out how best to do so isn't easy. The factors holding SMEs back vary from one place to another. Tax policies can dis-incentivize firms from growing. Elsewhere, access to finance dries up the moment businesses become too big for micro-lenders. Intermittent electricity and spotty internet access often render them uncompetitive. Sometimes firms themselves lack skilled managers and staff. They might struggle to meet international health and safety standards. 
The SMEs Competitiveness Outlook helps us understand the country-specific constraints most relevant to business success. The report systematically organizes them across three key pillars: the ability of SMEs to connect, compete and change. It then analyses these determinants of SMEs competitiveness at the level of companies, their immediate business environment and national policy.

Problems on any pillar, at any level, can be fatal to international competitiveness. For instance, the ability of a country's SMEs sector to supply quality goods in a timely and cost-effective manner is a function of firms' own abilities. But it also depends on the existence of a system to certify that their products meet international standards, and macro-level considerations like swift customs procedures.[3]

The report's findings will help governments and their partners identify which weaknesses are most harmful. The report's findings will help governments and their partners identify which weaknesses are most harmful. there were 8 networking issues, these were the networking in the aspect of learning and member development, production resource manage-ment, production development, processing to add value to their products, the standardization of their products, marketing and their produce/ products distribution, group/network management, and coordination and communication. In addition, the result showed that there were 4 aspects of guidelines and plans for the network development. These aspects were member/network development and network management, production development, marketing and packaging development, and monitoring system to guarantee the standardization of their products.[4]

Broadly speaking, however, Thailand comes out favorably in the report's analysis. Thai companies operate in a tradesupportive business environment, with Thailand scoring well on indicators for logistics and ease of trading. At the firm level, to skilled labor is still perceived as a constraint by SMEs. These are logical priorities for future government policy. From the problem above that on bossiness operation of SMEs Thailand, the world economy is slowing down and, the competitiveness in Asean markets. Its inspire researcher to study the factors lead to the business operations approach of SMEs in Pathumthani Province. The research finding will be an approach to help manager or owner of SMEs in Pathumthani Province improve their business operation in line with customer requirement and expand their market.

\section{Research Objectives}

The aim of the research are to investigate.

1.The importance level of factors lead to the business operations approach of SMEs in Pathumthani Province.

2.The characteristic of SMEs in Pathumthani Province

3.The relationship between the characteristic of SMEs and the importance level of factors lead to the business operations approach of SMEs in Pathumthani Province.

4.Business operation approach of Small and Medium Enterprise in Pathumthani Province.

\section{Scope Of The Research}

Scope of the content: this research were to study; nature of business operations of SMEs, the importance level of factors lead to The business operations approach of SMEs, the relationship between The nature of business operations of SMEs and the importance level of factors lead to The business operations approach of SMEs in Pathumthani Province, and Business Operation Approach of Small and Medium Enterprises in Pathumthani Province.

Scope of the population: data will collect from the manager or owner of SMEs in Pathumthani Province via accidental sampling of 385 respondents of unknown exactly population.

Location scope: the research area are in Pathumthani Province area.

\section{Hypothesis Of The Research}

Hypothesis 1: There are relationship between the nature of business operations of SMEs and the importance level of factors lead to the business operations approach of SMEs in Pathumthani Province.

Hypothesis 2 the importance level of factors lead to the business operations approach of SMEs in Pathumthani Province had related to business operations approach of SMEs in Pathumthani Province.

\section{Research Methods}

The purposes of this research are to study; 1) the importance level of factors lead to the business operations approach of SMEs in Pathumthani Province. 2) the characteristic of SMEs in Pathumthani Province.3) the relationship between the characteristic of SMEs and the importance level of factors lead to the business operations approach of SMEs in Pathumthani Province. 4) Business operation approach of Small and Medium Enterprise in Pathumthani Province. Research via quantitative methodology. Data were collected from executive or owner of SMEs in Pathumthani Thailand, by accidental sampling of 385 respondents of unknown exactly population. The research instrument were questionnaires. The data were then analyzed by computer software packages, statistic treatments were frequency, percentage, means, standard deviation, and ranking, Pearson Correlation, and Multiple Regression at statistical significance level of .05.

\section{Results}

1)Overall the importance level of factors lead to the business operations approach of SMEs in Pathumthani Province were at of a high importance level, raked by CV (Covariance) respectively were: Technology Development and upgrading of firms' technology, Innovation and information technology, Products, Distribution and supply chain, Business Environment, Price, Government promotion, Market promotion.

2) Overall and individual of the characteristic of SMEs in Pathumthani Province were at of a high importance level, raked by $\mathrm{CV}$ (Covariance) respectively were Average total 
turnover per year, Amount of employees, SMEs business operation.

3) There were moderate relationship level between the characteristic of SMEs and the importance level of factors lead to the business operations approach of SMEs in Pathumthani Province.

4) Business operation approach of Small and Medium Enterprise in Pathumthani Province. Business operation approach of Small and Medium Enterprises in Pathumthani Province were analyzed factors lead to the business operations approach of SMEs in Pathumthani Province by Multi Regression.

Table 1 Coefficients of factors lead to the business operations approach of SMEs in Pathumthani Province by

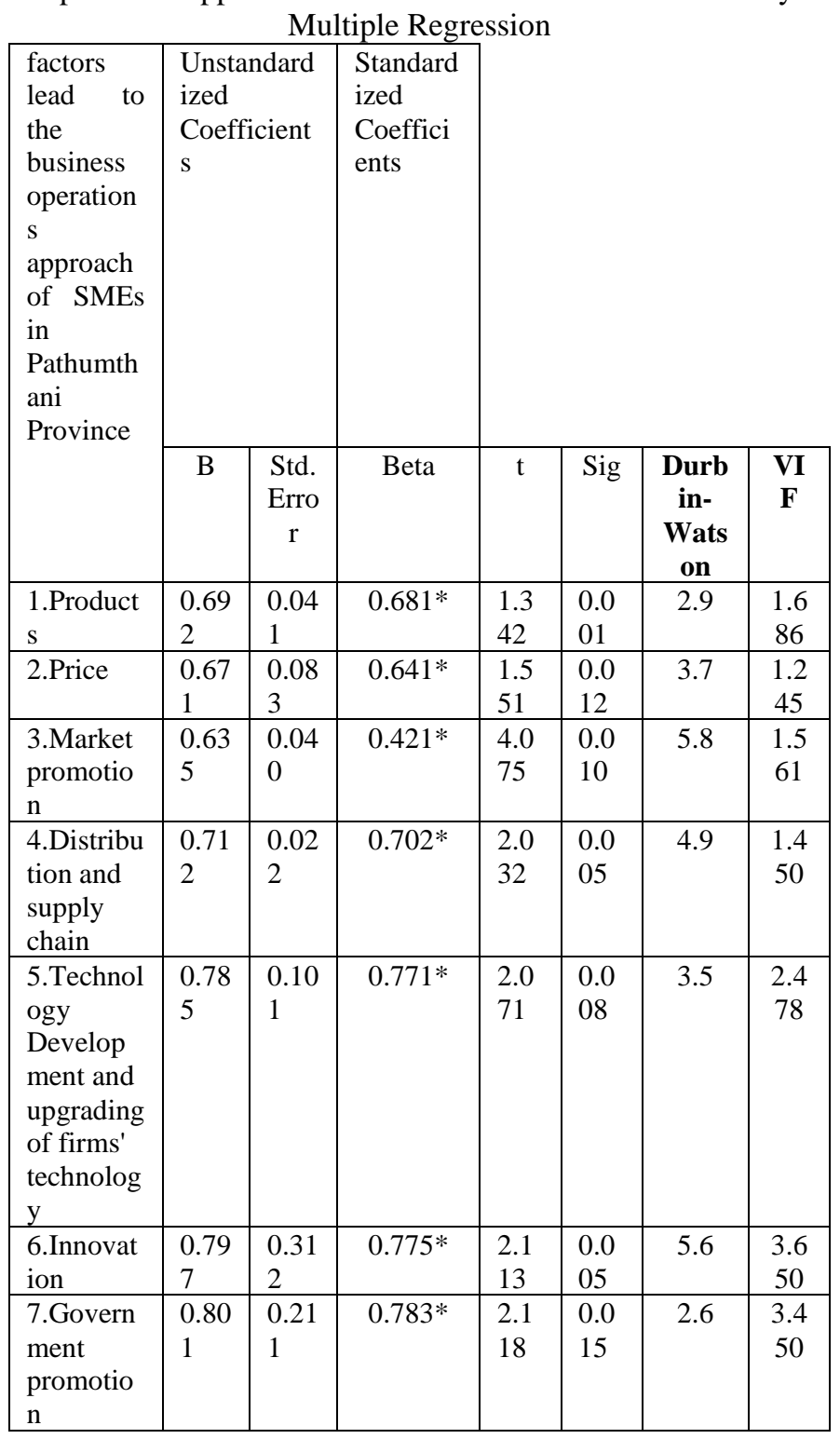

R square adjust $==0.713 \mathrm{R}$ square $=0.762$, Durbin-Watson $=3.132$

Standard error of the estimate $=0.321$

Note *Statistic Level .05

According to table 1 found that:

1)Coefficient of Durbin-Watson $=3.132$ between $2.6-5.8$ show that there were not relationship between Standard error of marketing factors [5]
2)Coefficient of VIF between1.245 - 3.650 less than 10 show that there were not relationship between of marketing factors (Oh. K, 2014)

Business operation approach of Small and Medium Enterprise in Pathumthani Province $=$ was 0.783 Government promotion, was 0.775.Innovation, was 0.771Technology Development and upgrading of firms' technology, was 0.702Distribution and supply chain, was 0.681Products, was 0.641 Price, was 0.421 Market promotion.

\section{Discussions}

Acceding to the research result found that: Business operation approach of Small and Medium Enterprise in Pathumthani Province $=$ was 0.783 Government promotion, was 0.775 Innovation, was 0.771 Technology Development and upgrading of firms' technology, was 0.702 Distribution and supply chain, was 0.681 Products, was 0.641 Price, was 0.421 Market promotion. Researcher would like to discussion as follow:

1. Government promotion was the first factors affected so the government should improve and concentrate on government promotion were easy access to government promotion, find new market, financial promotion (lower interest rate), increasing productivity, and Training and development the entrepreneur. It will help business operation of SMES better .783 units and it consistent with the research of Sumaree Swang and Outher[6] the factors that affect success and develop a success model to promote small and medium enterprises (SMEs) in the northern provinces of Thailand. This research aimed to study the factors that affect success and develop a success model to promote small and medium enterprises (SMEs) in the northern provinces of Thailand. The results showed that the factors affecting the success of small and medium enterprises (SMEs) in the northern provinces of Thailand were the combination of demographic factors and business factors, were government promotion socially financial factors.

2.Innovation was the second factors affected so the entrepreneur should improve and concentrate on innovation were take action and quickly for new products, funding for innovation, .empower employees that provide value in new ways, embrace a multi-faceted approach to Innovation, starting at the bottom, choose approach to innovation Metrics Wisely. It will help business operation of SMES better 0.775 units and it consistent with the research of Tawamin Kruasom [7]Creating a Competitive Advantage for Thai SMEs towards Thailand 4.0 The objective for this research was to explore how Thai SMEs reached a competitive advantage under Thailand 4.0 era. The case of Ban Nong Khon Village located in Ubon Ratchathani Province, Thailand was selected purposively by considering in both of its strengths and operation period. This village is popular in various handmade products and has granted many awards from Thai government. The in-depth interview and focused-group interview were employed through 15 members by qualitative approach. Triangulations were strictly concerned with a data interpretation. The findings shown that the competitive advantage of Thai SMEs was 
driven from being learning organization and organization creativity.

3. Technology Development and upgrading of firms' technology was the third factors affected so the entrepreneur should improve and concentrate on technology Development and upgrading of firms' technology were service processes and production with automation, research and development for growth (R\&D), improve production process with new technology, and management by information technology. It will help business operation of SMEs better 0.771 units and it consistent with the research of Mohd Hafeez and Other [8] had studied Operational Excellence on Small and Medium Enterprises in Malaysia. The objective of the study is to investigate the factors that influencing the operational excellence on SMEs sectors. Research found that soft factors, hard factors and external environment factors especially technology Development and upgrading of firms' technology.

4. Distribution and supply chain was the fourth factors affected so the entrepreneur should improve and concentrate on distribution and supply chain were distribution through omi channel (online, in a convenience store, or by phone), online channel (Facebook, Instragram, line, YouTube, Google, or other on line charnel, proper coordination and collaboration with channel partners, Convenience Store and modern trade, and direct sales by cataloged and delivery. It will help business operation of SMEs better 0.702 units and it consistent with the research of Mohammed R. A. Siam [9]Social media and corporate communication antecedents of SMEs sustainability performance: A conceptual framework for SMEs of Arab world. The purpose of this paper is to discuss the role of social media and corporate communication as a key success factor of small- and medium-sized enterprises (SMEs) operating in Arab world. This is a conceptual study and has shed light on the notable existing literature on these issues and particularly of Arab context. The social media has emerged as an opportunity for marketing communication, and it is the easiest cheapest way of advertising products and services. Social media provides a platform wherein a company or firm can target a diverse audience and can create an effective communication strategy.

5. Products was the firth factors affected so the entrepreneur should improve and concentrate on products by produced unique products differentiate than other, packaging and its availability, product quality superiority, and its image or appear, products usefulness in boosting business growth and morale, achievement of quality awards, particularly ISO standards. . It will help business operation of SMEs better 0.681 units and it consistent with the research of Tanakorn Limsarun [10] The Sustainability of Small and Mediumsized Enterprises (SMEs) in A Digital Economy Era. Research finding market barriers and enhance the competitive advantages especially in new products of SMEs and human resources.

6. Price was the sixth factors affected so the entrepreneur should improve and concentrate on pricing by setting reasonable price, high price for a new high-end product, psychological pricing $(99,199.999$ ETC.), multiple pricing appropriate to the size of products, penetrating the market with low price. It will help business operation of SMEs better .641units and it consistent with the research of
Phanthipa Srinammuang[11] Critical Success Factors of Thai SMEs in the new Product and Service Development Sector SMEs plays a significant role of national economic development as it creates jobs and helps release the poverty issue. This research aims at identifying the critical success factors of SMEs in the sector of the New Product and Service Development (NPSD) whereas the new entrepreneurs need supports for all aspects: capital, business knowledge especially setting the price of SMEs

7. Market promotion was the seventh factors affected so the entrepreneur should improve and concentrate on market promotion by through review and advertise on social media, promote via exhibition and event related to products, creating awareness about product, discount or raffle, and using mass marketing to gain a competitive edge over its competitors. It will help business operation of SMEs better .421units and it consistent with the research of Phanthipa Srinammuang [12] Critical Success Factors of Thai SMEs in the new Product and Service Development Sector SMEs plays a significant role of national economic development as it creates jobs and helps release the poverty issue. This research aims at identifying the critical success factors of SMEs in the sector of the New Product and Service Development (NPSD) whereas the new entrepreneurs need supports for all aspects: capital, business knowledge, marketability and promotion.

\section{Recommendations}

According to research result it can suggestion that:

1. Government promotion the government should improve and concentrate on government promotion were easy access to government promotion, find new market, financial promotion (lower interest rate), increasing productivity, and training and development the entrepreneur.

2.Innovation entrepreneur should improve and concentrate on innovation were take action and quickly for new products, funding for innovation, empower employees that provide value in new ways, embrace a multi-faceted approach to Innovation, starting at the bottom. Choose approach to innovation metrics wisely.

3. Technology Development and upgrading of firms' technology was the third factors affected so the entrepreneur should improve and concentrate on technology Development and upgrading of firms' technology were service processes and production with automation, research and development for growth (R\&D), improve production process with new technology, and management by information technology.

4. Distribution and supply chain was the fourth factors affected so the entrepreneur should improve and concentrate on distribution and supply chain were distribution through omi channel (online, in a convenience store, or by phone), online channel (Facebook, Instragram, line, YouTube, Google or other on line charnel, proper coordination and collaboration with channel partners, Convenience Store and modern trade, and direct sales by cataloged and delivery

5. Products was the firth factors affected so the entrepreneur should improve and concentrate on products by produced unique products differentiate than other, packaging and its availability, product quality superiority, and its image or appear, products usefulness in boosting business growth and 
morale, achievement of quality awards, particularly ISO standards.

6. Price was the sixth factors affected so the entrepreneur should improve and concentrate on pricing by setting reasonable price, high price for a new high-end product, psychological pricing $(99,199.999$ ETC.), multiple pricing appropriate to the size of products, penetrating the market with low price.

7.Market promotion was the seventh factors affected so the entrepreneur should improve and concentrate on market promotion by through review and advertise on social media, promote via exhibition and event related to products, creating awareness about product, discount or raffle, and using mass marketing to gain a competitive edge over its competitors

\section{References}

[1] Gonzalez, A. 2018) Challenges ahead for Thailand's SMEs Retrieved June, 20,2019 form https://www. bangkokpost.com/opinion/opinion/748676 /challenges-ahead-for-thailand-smes

[2] Srivirot S.and Lusawat L.(2016)Thai SMEs and Risk of Cost in the ASEAN Free Trade Area (AFTA) EAU Heritage Journal Social Science and Humanities, 6 (1) (2016): Januari-April, 1-20

[3] Ibid

[4] Yoopraser B. et al ()Guidelines on Developing the Network of Young Generation of Agricultural SMEs Entrepreneurs, rincess of Naradhiwas University Journal, 8(3), 140-153. Retrieved from https://li01.tcithaijo.org/index.php/pnujr/article/view/654 15

[5] Oh, K. (2014).The Effects of Brand, The international journal of business in society, Vol. 16 Issue March USA.

[6] Kruasom T.(2018) Creating a Competitive Advantage for Thai SMEs towards Thailand 4.0 Era. Faculty of Management Science, Ubon Ratchathani University

[7] Swang S. et al (2019) the factors that affect success and develop a success model to promote small and medium enterprises (SMEs) in the northern provinces of Thailand. Faculty of Business Administration, Rajamangala University of Technology Thanyaburi
[8] Hafeez M.et al (2016) Operational Excellence on Small and Medium Enterprise in Malaysia. Conference Paper Conference: SOCIAL SCIENCES POSTGRADUATE INTERNATIONAL SEMINAR (SSPIS) 2016, At Sains@USM, Bukit Jambul, Penang, Malaysia

[9] Mohammed R. A. Siam (2019) Social media and corporate communication antecedents of SME sustainability performance: A conceptual framework for SMEs of Arab world. University Utara Malaysia Northern border University.

[10] Limsarun T. (2015) The Sustainability of Small and Medium-sized Enterprises (SMEs) in A Digital Economy Era Lecturer of MBA Department Siam University 38 Phetkasem Road Phasicharoen Bangkok 10163

[11] Srinammuang P. (2019) Critical Success Factors of Thai SMEs in the new Product and Service Development Sector. Kasetsart University, Thailand

[12] Ibid 